fits each quadrant of the screen appropriately, it is possible to cover the whole of a two metre screen with it.

An illustration is inset Fig. 1, showing the effect of gold-headed pins marking out a scotoma as seen through the protractor mounted as a wall-roller blind. The instrument as shown is inexpensive, and is easily affixed to a wall or an easel.

I am obliged for assistance in the development of this instrument to Messrs. H. M. Traquair, McKie Reid and John Pike.

The instrument is made by Rayner \& Co., 100, New Bond Street.

The instrument can be further improved by a system of even illumination from two "Holophane" reflectors, which can hold 60 watt frosted bulbs on iron brackets. These lamps are mounted on iron brackets and at a position $2 \mathrm{ft}$. above and in front of the upper corners of the screen with a slight inclination downwards and inwards. This is calculated to give an even illumination of 10 foot-candles over the whole black surface. This intensity of illumination is the same as that now in use on the Bjerrum screen at Moorfields.

\title{
EXTENSIVE OCULO-PALPEBRAL NEOPLASM; EXCISION OF LIDS AND ENUCLEATION OF THE EYEBALL, FOLLOWED BY OCCLUSION OF THE ORBIT
}

BY

\section{Professor Dr. Elena Pușcariu}

Roumania

IN our practice it is not unusual to meet with neoplasms of the bulb and lids involving the orbit, whether the tumour had in the beginning an epibulbar, or as more frequently, a palpebral origin.

One would vainly look in the ocular surgical treatises for a method to be followed in such cases, which have been probably considered as incurable, and indicated only for radiotherapy.

For such cases I have long since imagined and practised a method which always gives full satisfaction.

The intervention to be here described, should advantageously be preceded by a preparatory treatment in order to get the surface of the tumour as clean as possible, and to destroy the suppuration germs by means of antiseptic dressings (preferably compresses with Dakin's fluid).

As anaesthetics, if the patient be not too nervous, morphia will be sufficient, associated with retrobulbar injections of novocaineadrenalin. The same solution is used for the infiltration of the integuments needed for the occlusion of the orbit. 


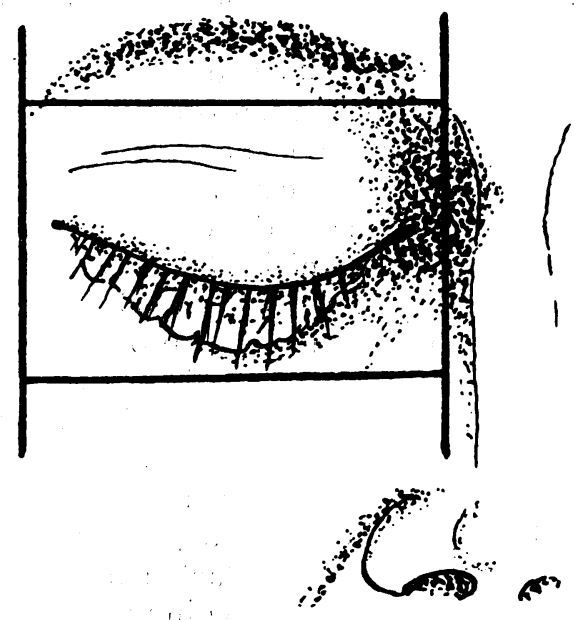

FIG. 1.

The four incisions tangential to the borders of the orbit.

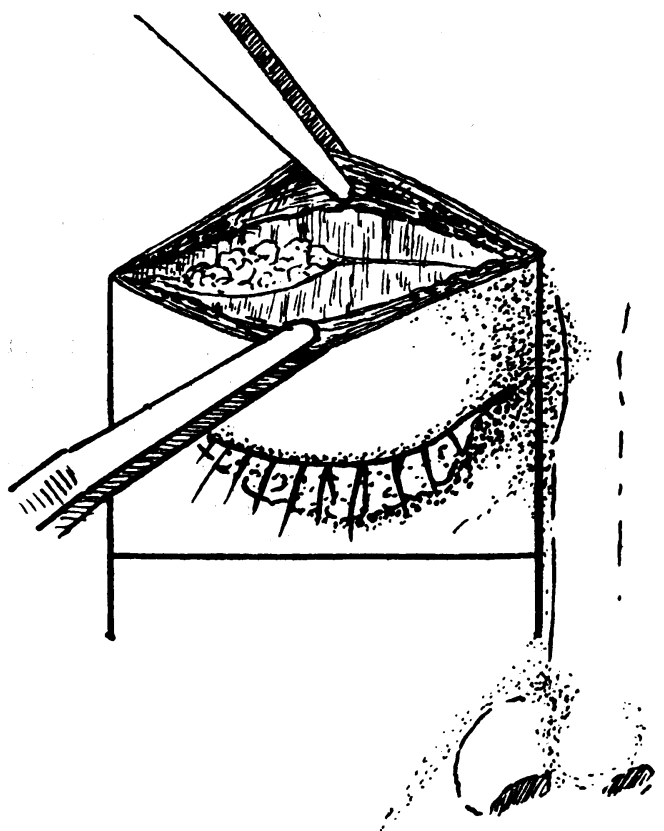

FIG. 2.

The section of the orbital aponeurosis. 
The intervention includes the following steps:-

(1) Four linear incisions tangent to the four orbital borders uniting with one another at right angles. The incisions involve the skin and subjacent musclès.

(2) Recognition of the limits of the supra-orbital insertion of the orbital aponeurosis, and incision of it. This opens up the cellular

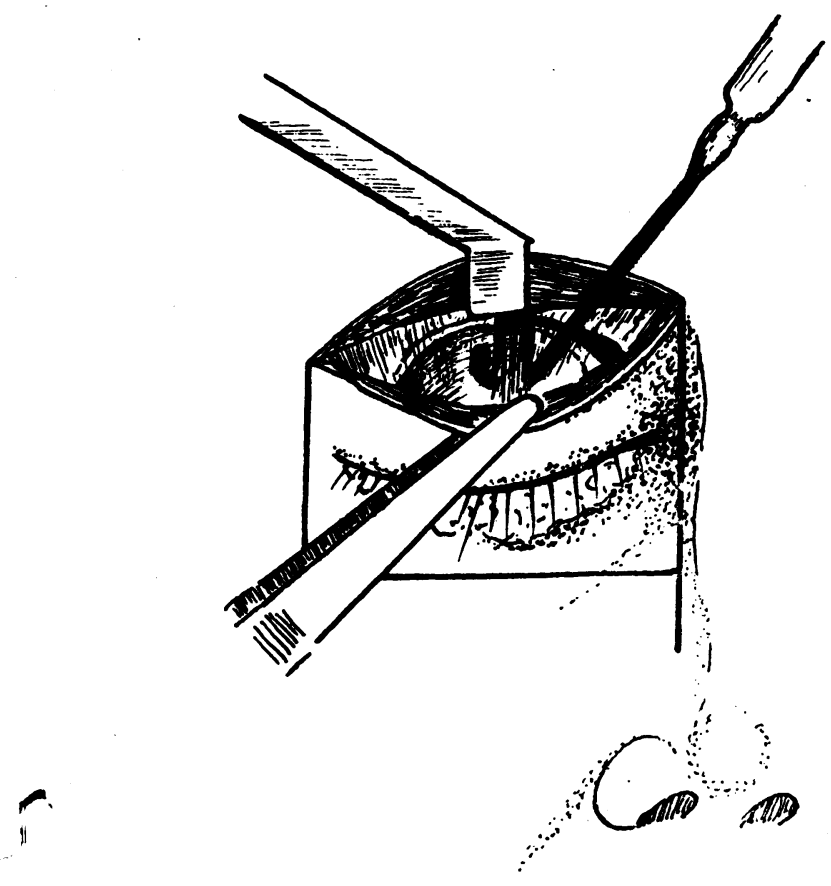

FIG. 3.

Section of the muscles.

orbital tissue and reveals the girth of the rectus superior which is divided after being lifted up on the strabismus hook (Figs. 2 and 3). We repeat the same procedure for the other three incisions, separating the aponeurosis from its orbital insertions, cutting the other three muscles and sectioning also the capsule of Tenon, which extends between them.

We usually proceed after the incision of the superior rectus to that of the rectus externus, then to the rectus inferior, and when we reach the internal section we first detach the insertion of the orbicular tendon which is seized with a haemostatic forceps. This will permit us to proceed after the section of the rectus internus to the third step of our intervention, which is the luxation of the eyeball and the section of the optic nerve, and that of the last muscles and 
adhesions (Fig. 4). The piece taken out as a whole appears as in Fig. 5.

In order to perfect the operation we must now cover again the borders of the orbit and the healthy tissues which fill it. For this, we cut two cutaneous flaps, one frontal, the other facial, extending the vertical incisions to the necessary lengths. The flaps, well dissected, are advanced one towards the other in face of the orbit, and are sutured about its centre. We then suture the vertical

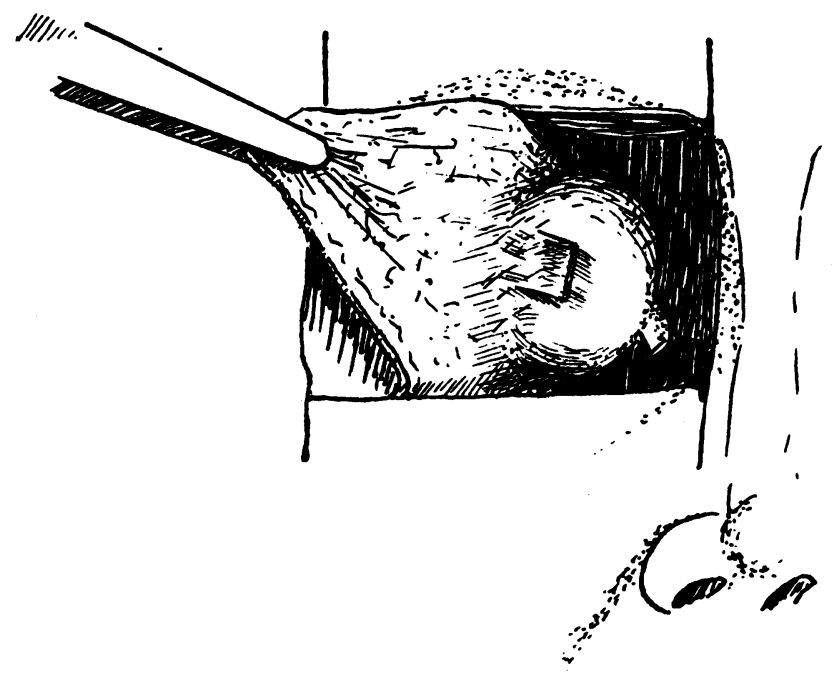

Fig. 4

The luxation of the eyeball to the outside, and the section of the optic nerve.

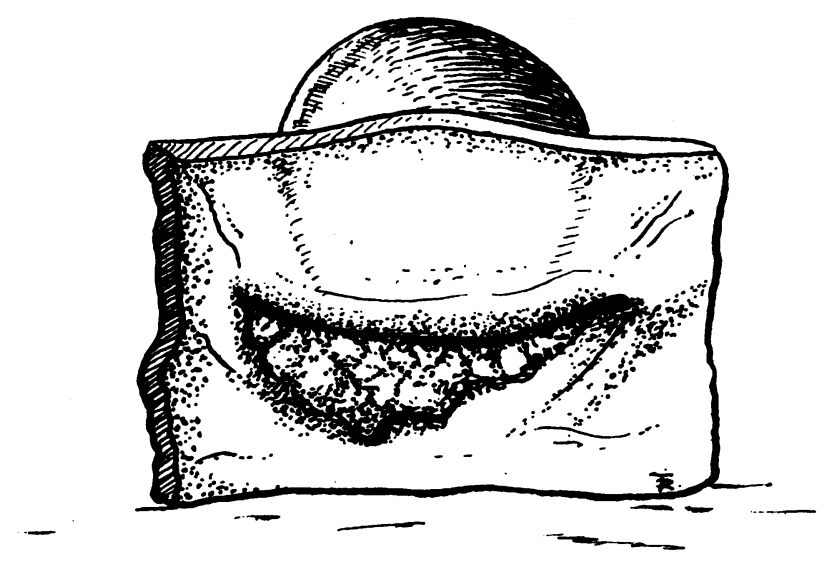

FIG. 5.

Lids and eyeball excised as a whole. 
incisions. Finally the result is the presence of the three incisions sutured before the orbit in the shape of an $\mathrm{H}$.

There are, however, cases (as in the description we give below) where the last step is complicated by the great extension of the tumour which requires a very large and irregular incision, and flaps as previously described would be insufficient. My observation and the included photographs, will show the manner in which we have acted in such cases.

Case I. Palpebro-ocular epithelioma.

C. P., male, aged 66 years, a countryman, admitted as an in-patient of the Jassy Ophthalmological clinics on January 26, 1933.

He gave the following history: Denied syphilis, does not smoke. Thirty years ago, he suffered from redness and subjective troubles in each eye. Two years ago, a small ulcer appeared on the edge of his right lower lid. This has gradually extended to the whole edge and has invaded a portion of the lid itself. Last summer it reached the inner canthus and mounted to the upper lid. Later on, the ulceration advanced towards the outer canthus. Before Christmas, the eyeball became congested and the sight rapidly failed completely. For the past three weeks he has suffered with severe headaches, hemicrania and intra-ocular pains.

On examination, his right eye appears watery and shows marked photophobia. The whole ciliary edge, from the internal canthus to the external, is replaced by a vegetant mamillary tissue, with great, shiny, smooth, pinkish embossments. The anterior edge, irregular and festooned shows only 3-4 eyelashes.

On separating the lids, one sees that this neoplastic tissue involves the whole palpebral conjunctiva up to the conjunctival fornices. It occupies both corners and about $1 / 2 \mathrm{~cm}$. of the extremity of the upper lid. On these portions, the ciliary edge is also destroyed and replaced by vegetant tissue. This tissue is hard and is not adherent to the subjacent regions. The destruction of the palpebral edge uncovers the bulbar conjunctiva in its inferior part, where it appears very congestive and oedematous, at about $5 \mathrm{~mm}$. from the corneal limbus.

The cornea is ulcerated, yellowish, and stains with fluorescein over its whole surface. The blood vessels surpass the supposed limit of the sclero-corneal limbus.

The patient looked asthenic, rather emaciated, with dry skin. Nothing abnormal was found in the lungs, heart or abdomiual organs. The preauricular gland was enlarged. The sero-reactions of BordetWassermann and Meinike were negative. Arterial tension 12/9.

The smear made from the ulcer showed very many polymorphonuclear cells and a few gram-positive cocici.

The patient was treated with $\mathrm{Hg}$ oxycyanide washings and dressings. He was operated on February 8, 1933. Anaesthesia 
with morphia and retrobulbar injections of novocaine-adrenalin. Extirpation of both lids, enucleation of the eyeball, occlusion of the orbit according to the described technique by advancement of two cutaneous flaps.

Subsequent progress. The local post-operative course was perfectly normal. The patient, however, two days later developed a mild attack of influenza with fever. On February 15 the stitches were removed, the flaps were perfectly healed. The patient left the clinics on February 27.

Case II. Oculo-palpebral epithelioma.

S., male, aged 72 years, a countryman, was admitted as an inpatient to the Ophthalmological clinics on April 21, 1932. He gave the following history:-

Three years ago he began to be troubled with itching and scalding of the left upper lid. These symptoms disappeared during the winter, and recurred next summer, being accompanied this time with pain. For a year, a small tumour has appeared, situated in the middle of the lid under the eyebrow. The tumour soon became ulcerated and bleeding. This ulceration has invaded the whole upper lid and has extended to the lower one, being most accentuated at the internal canthus. The eyeball became congested and the sight very much diminished.

On examination both lids of his left eye and the lateral part of the root of the nose appear destroyed, occupied by a vegetant ulceration with irregular margins, reaching the eyebrow, which is also destroyed. The ciliary edges have disappeared through the action of this vegetant tissue. One can distinguish only the external third of the inferior lid. The tumour is covered with dirty brown crusts under which the surface bleeds. The tumour is hard, but movable except for the internal portion.

On separating the vegetant masses and uncovering the eyeball, the cornea appeared cloudy, ulcerated and surrounded by a vegetant red conjunctiva. This appearance became accentuated towards the conjunctival fornices. The palpebral portions of the conjunctiva were also invaded by the neoplastic tissue. The patient appeared weak and anaemic.

The operation was performed on May 5. Morphia 0.03 , and local intradermal anaesthetics.

The lids and all integuments invaded by the cancer were excised, and the eyeball enucleated. The orbit was occluded with a frontomalar flap, which is advanced and torsioned, and with a free graft from the great frontal flap.

The conjunctiva was totally invaded by the neoplastic tissue and the tumour well adherent to the internal part of the orbita. The bone seems covered, however, with apparently normal periosteum. The intra-orbital tissue is not invaded. 


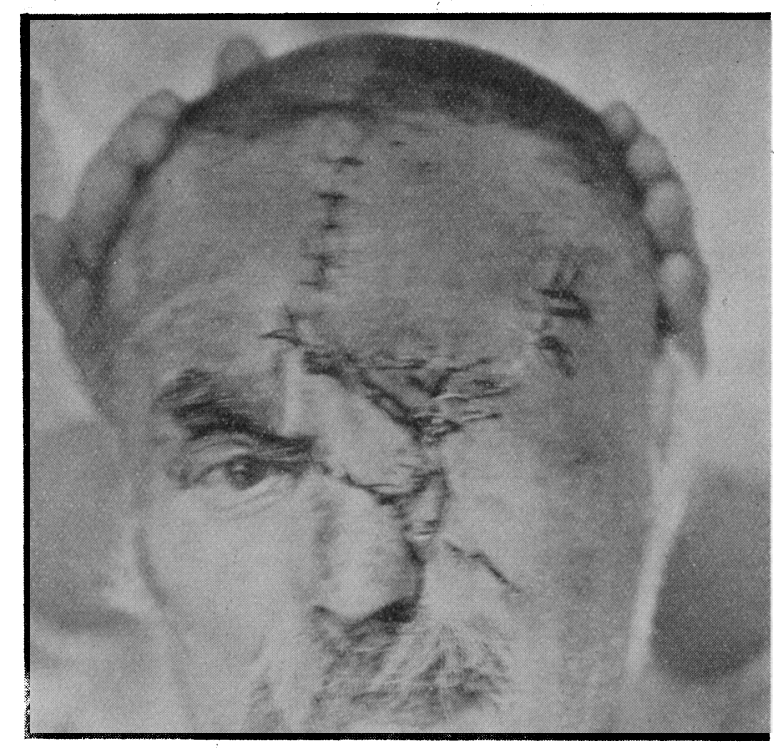

Fig. 6.

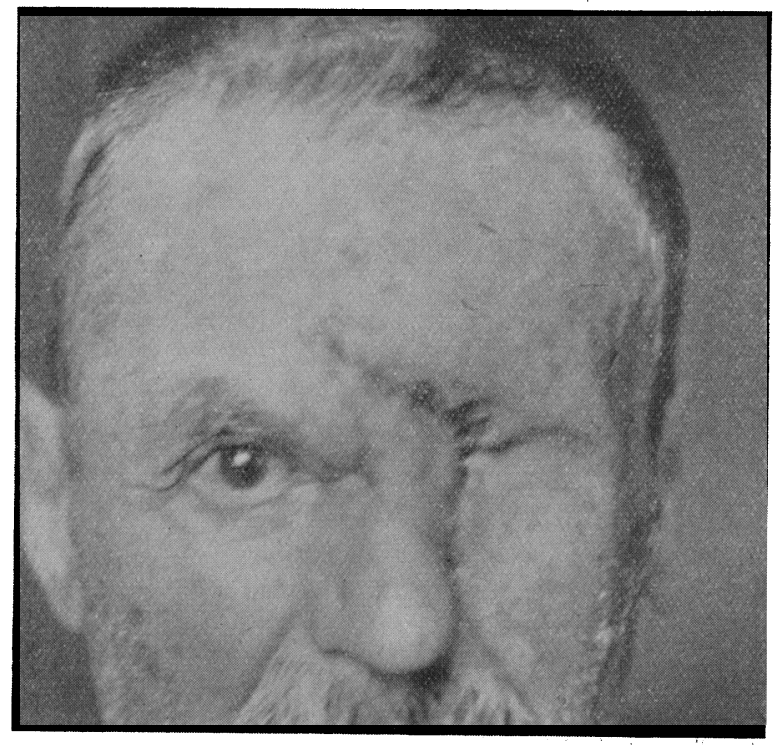

FIG. 7. 
May 13, 1932. Second intervention under local anaesthesia (adrenalin-novocaine). The fold from the bridge of the nose was excised.

May 31, 1932, flaps and graft are totally healed.

June 8,1932 . The patient left the clinics. His general appearance seems much improved.

Microscopic examination: Basocellular epithelioma.

\section{Mr. J. B. LAWFORD}

THE death of Mr. Lawford on January 3 not only deprives British Ophthalmology of one of its acknowledged heads but is an especially heavy blow to this Journal.

The wings of Azrael have indeed overshadowed the ophthalmic fraternity during the past twelve months: Treacher Collins, Priestley Smith, Herbert Fisher, Maddox and now Lawford.

A memoir, by one who knew him well, will appear in our next number; here we wish to emphasize the loss which the Journal has sustained.

Lawford was elected Chairman of the Editorial Committee on our foundation at the end of the year 1916. But when Mr. Jessop died in February, 1917, the Journal was barely six weeks old. It was a critical time. Lawford became Senior Managing 1)irector of the Company which owns the Journal and with Leslie Paton did a great deal of work to establish it on a sound financial basis and achieved a complete success. At the Annual Meeting, 1926, Lawford resigned his post.

He was an active member of the Editorial Committee from the start until his health broke down about a year ago, and though no longer able to attend our meetings, he continued to work for us until the end. He had had much experience of ophthalmic journals, for he edited the Ophthalmic Review for some years before the British Journal of Ophthalmology was established.

Lawford's name was known all over the Empire. His sterling qualities, his uprightness of character and his logical mind made him an ideally wise and kindly adviser in cases of difficulty, and he certainly never spared time or trouble in the interests either of his friends, or of this Journal.

His public work-whether in connexion with the Ophthalmological Society of the United Kingdom, of which he had been President and Treasurer; with the Council of British Ophthalmologists, of which he had been Chairman; or with the Committee on the Causes and Prevention of Blindness, as well as his hospital work, was carried out with meticulous conscientiousness.

It is with a very special sense of loss that we, of the Editorial Committee, say Ave atque Vale. 